\title{
Behçet's syndrome with gangrenous bilateral lower limbs
}

\author{
Yathish Gattimallanahali, Gurmeet Mangat, Balakrishnan Canchi, Girish Kakade
}

Department of Rheumatology, PD Hinduja Hospital and Medical Research Centre, Mumbai, Maharashtra, India

\section{Correspondence to} Dr Yathish Gattimallanahali, yathish_gc@yahoo.co.in

Accepted 21 January 2016

\section{DESCRIPTION}

A 25 -year-old Indian woman presented with recurrent oral and genital ulcers that had started in 2008 . She had suffered from posterior uveitis that same year and been treated with oral prednisolone $40 \mathrm{mg} /$ day tapered over 6 months, after which she recovered fully with complete restoration of vision without the need for any other immunosuppressive agents. In 2009, she developed acute onset gangrene of the right foot, which needed above-ankle amputation (figure 1). In 2011, she consulted a rheumatologist for a non-healing ulcer of the right thigh. A diagnosis of Behçet's syndrome was made and she was treated with prednisolone $1 \mathrm{mg} / \mathrm{kg}$ taper along with azathioprine $100 \mathrm{mg} /$ day. She did not have a family history of Behçet's syndrome nor of any other autoimmune disorder. Over the next 6 months, there was complete resolution of the skin and orogenital ulcers. She was in remission until July 2015, on maintenance steroid and azathioprine, at which time she initially consulted us for acute onset gangrene of the left foot (figures 1 and 2). Physical examination revealed left foot gangrene with a clear line of demarcation and absent left dorsalis pedis and posterior tibial arterial pulsation.

Laboratory findings showed an increase in serum C reactive protein $(71.16 \mathrm{mg} / \mathrm{L})$. Rheumatoid factor, antinuclear antibodies, antineutrophil cytoplasmic antibodies (ANCA), antiphospholipid antibodies (APLA) and lupus anticoagulant were all negative. CT angiogram showed no flow in left anterior tibial and dorsalis pedis arteries (figure 3 ). The patient underwent above-ankle amputation of the left foot. Histopathology of the amputated foot showed arterial wall inflammation with thrombosis and inflammatory infiltrate in the dermis and subcutaneous tissue. An intravenous pulse of methylprednisolone $500 \mathrm{mg} /$ day for 3 days was

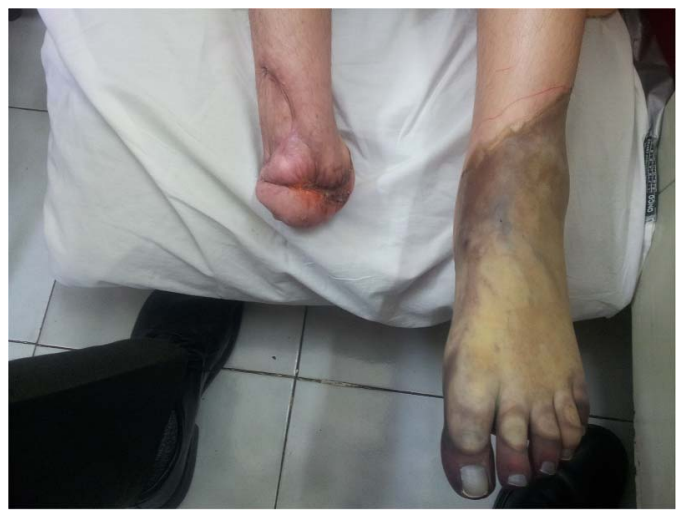

Figure 1 Amputated right foot and left foot gangrene with clear line of demarcation.

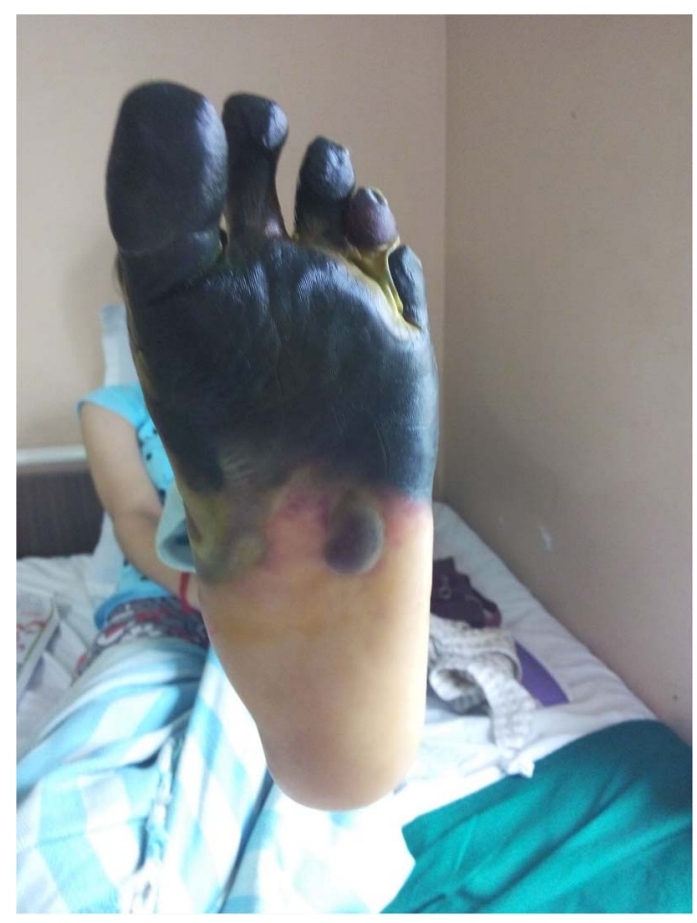

Figure 2 Gangrenous left foot.

administered and a course of intravenous pulses of cyclophosphamide $500 \mathrm{mg}$ every fortnightly was advised. At the patient's latest follow-up, she had received 6 pulses of intravenous cyclophosphamide and was on $10 \mathrm{mg}$ prednisolone. The amputated stump had healed well and she was undergoing active physiotherapy and rehabilitation (figure 4).

Behçet's syndrome is a chronic, relapsing and debilitating systemic vasculitis of unknown aetiology, characterised by recurrent oral ulcers, genital ulcers, ocular and skin involvement, and other multisystem features. It can cause significant morbidity leading to functional impairment, disability affecting quality of life and mortality. There are no specific diagnostic tests for Behçet's syndrome, the diagnosis is made on the basis of the clinical picture, with typical features balanced by exclusion of other differential diagnoses. The differential diagnosis of a young patient presenting with gangrene of limbs is wide, and includes ANCA-associated vasculitis, polyarteritis nodosa, APLA syndrome and other procoagulant states. Careful exclusion of all these conditions with appropriate investigations is essential.

Genome-wide association studies (GWAS) have confirmed HLA-B51 association, however, the potential interactions of this allele with other genetic and non-genetic risk factors, and with disease phenotype, is yet to be confirmed. ${ }^{1}$ In our 


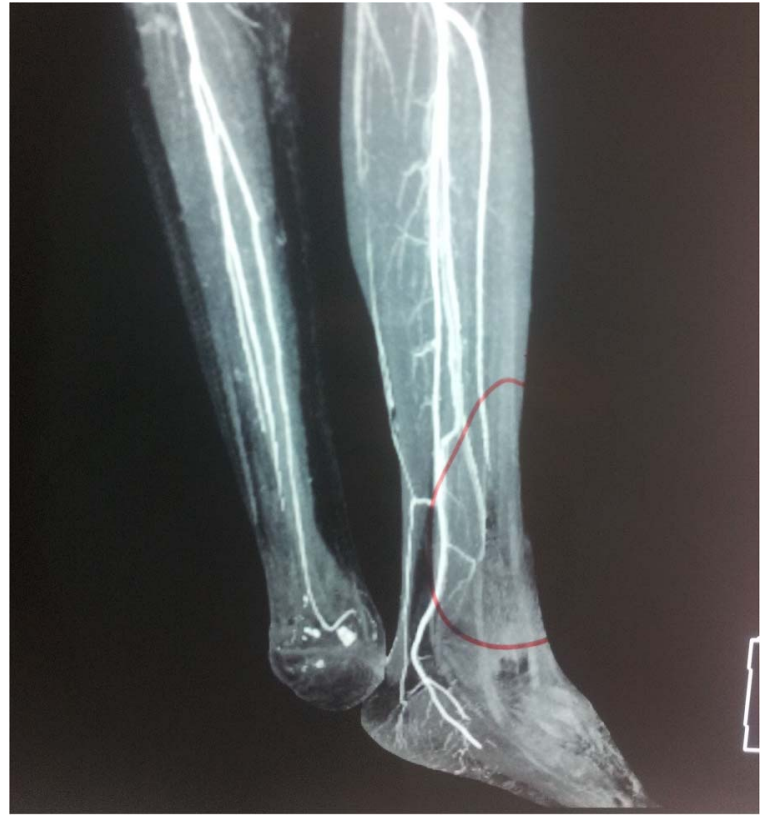

Figure $3 \mathrm{CT}$ angiography of lower limbs showing no flow in left anterior tibial and dorsalis pedis artery.

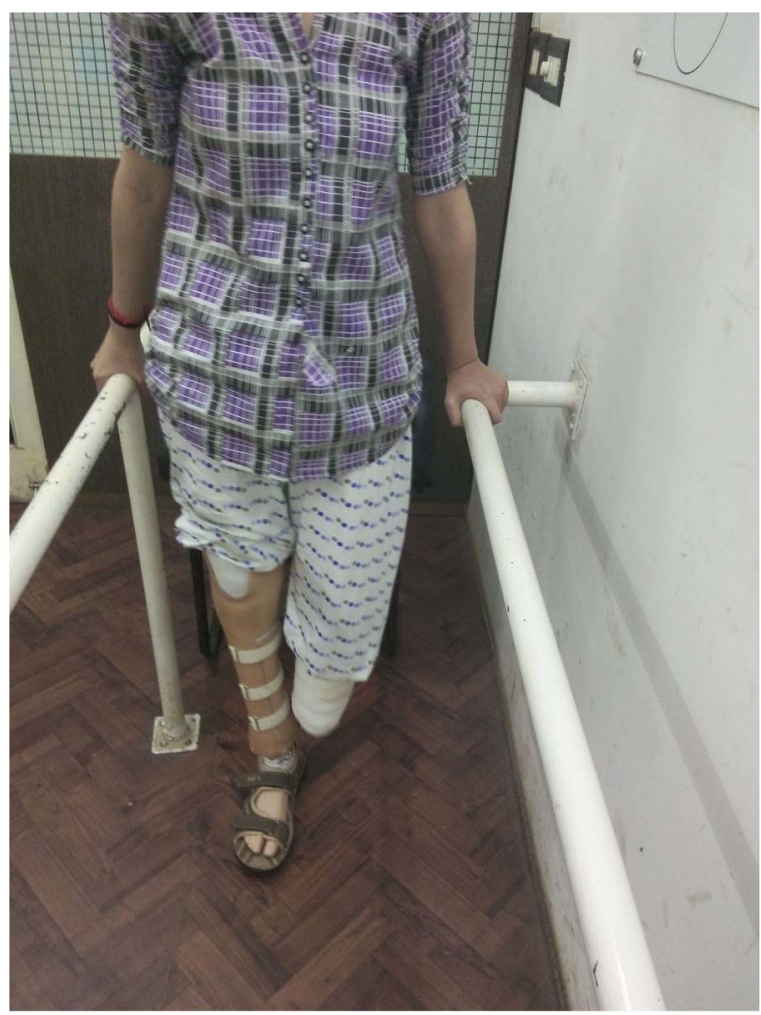

Figure 4 Patient undergoing active physiotherapy and rehabilitation with right foot prosthesis. patient, who was already an established case of Behçet's syndrome with a proven vasculitis, HLA-B51 was not carried out due to financial constraints and also as it would not have changed the course of management.

Arterial involvement is rare and has been reported in about $1-12 \%$ of patients with Behçet's syndrome. ${ }^{2}$ Any part of the arterial tree can be affected, with aneurysms or occlusions in the abdominal aorta, carotid, pulmonary, femoral and popliteal arteries. Disease seems more aggressive with high mortality in patients who have their disease onset at 14-24 years of age. ${ }^{3}$ With time, the disease seems to become less aggressive, with a smaller number of exacerbations and decreased mortality. Arterial involvement in Behçet's syndrome is very rare in the Indian population-reported only in a few cases. In spite of its rarity, it becomes very important to keep vasculitis as one of the differentials in any young patient with thrombotic events, as missing the diagnosis can lead to devastating complications.

The treatment of arterial involvement involves a combination of steroids and cyclophosphamide as a first-line therapy, progressing to infliximab in severe refractory and life-threatening cases. Surgical repair of peripheral arterial aneurysms, if indicated, should be performed after controlling the disease with adequate immunosuppression. Anticoagulation is not used unless there is a prothrombotic tendency in the subject and an absence of aneurysms.

\section{Learning points}

- Vasculitis in Behçet's syndrome can occur in spite of the patient being on immunosuppressive drugs.

- Vasculitis in Behçet's syndrome needs early diagnosis and aggressive management.

- Frequent monitoring is required, especially in young patients who have higher risk for vascular events.

Twitter Follow Yathish Gattimallanahali at @yathishgc45

Competing interests None declared.

Patient consent Obtained.

Provenance and peer review Not commissioned; externally peer reviewed.

\section{REFERENCES}

1 de Menthon M, Lavalley MP, Maldini C, et al. HLA-B51/B5 and the risk of Behçet's disease: a systematic review and meta-analysis of case-control genetic association studies. Arthritis Rheum 2009;61:1287-96.

2 Saadoun $D$, Asli B, Wechsler $B$, et al. Long-term outcome of arterial lesions in Behçet disease: a series of 101 patients. Medicine (Baltimore) 2012;91:18-24.

3 Kural-Seyahi E, Fresko I, Seyahi N, et al. The long-term mortality and morbidity of Behcet syndrome: a 2-decade outcome survey of 387 patients followed at a dedicated center. Medicine (Baltimore) 2003;82:60-76. 
Copyright 2016 BMJ Publishing Group. All rights reserved. For permission to reuse any of this content visit http://group.bmj.com/group/rights-licensing/permissions.

BMJ Case Report Fellows may re-use this article for personal use and teaching without any further permission.

Become a Fellow of BMJ Case Reports today and you can:

- Submit as many cases as you like

- Enjoy fast sympathetic peer review and rapid publication of accepted articles

- Access all the published articles

- Re-use any of the published material for personal use and teaching without further permission

For information on Institutional Fellowships contact consortiasales@bmjgroup.com

Visit casereports.bmj.com for more articles like this and to become a Fellow 